\title{
Identification of fossilized eggshells from the Taung hominin locality, Taung, Northwest Province, South Africa
}

\author{
Brian F. Kuhn, Kristian J. Carlson, Philip J. Hopley \\ Bernhard Zipfel, and Lee R. Berger
}

\begin{abstract}
While an avian component within faunal remains from the Dart Deposits, Taung, South Africa, has been discussed for nearly a century, the taxa present have not been identified to species. Here we conduct a systematic analysis of fossilized eggshell fragments in order to document the presence of specific avian taxa at Taung during the Plio-Pleistocene. A comparative analysis of surface morphology and surface curvatures of fragmentary eggshells eliminated all but three extant avian taxa as potential sources for the fossilized fragments: a large eagle, an eagle owl (Bubo sp.) or a guinea fowl (subfamily Numidinae). The likelihood for each of these three taxa as a source is discussed by evaluating surface curvature matches between the fossilized fragments and extant eggshells. The two most complete fossil eggshells recovered from Taung have distinct carbon isotope signatures indicating that they belong to two different, granivorous and carnivorous, guilds. While these identifications contribute to the debate over whether or not there was an avian agent of collection for the Taung fossils, including perhaps the Taung Child, by establishing direct evidence for a raptor component in the Taung faunal assemblage, they cannot address specific predator-prey behaviour.
\end{abstract}

Brian F. Kuhn. Evolutionary Studies Institute, University of the Witwatersrand, Johannesburg South Africa brian.kuhn@wits.ac.za

Kristian J. Carlson. Evolutionary Studies Institute, University of the Witwatersrand, Johannesburg South

Africa

and Department of Anthropology, Indiana University, Bloomington, Indiana, USA

kristian.carlson@wits.ac.za

Philip J. Hopley. Department of Earth and Planetary Sciences, Birkbeck, University of London, London, England; and Department of Earth Sciences, University College London, London, England p.hopley@ucl.ac.uk Bernhard Zipfel. Evolutionary Studies Institute, University of the Witwatersrand, Johannesburg South Africa bernhard.zipfel@wits.ac.za

Lee R. Berger. Evolutionary Studies Institute, University of the Witwatersrand, Johannesburg South Africa lee.berger@wits.ac.za

PE Article Number: 18.1.11A

Copyright: Paleontological Society March 2015

Submission: 25 November 2014. Acceptance: 25 February 2015

Kuhn, Brian F., Carlson, Kristian J., Hopley, Philip J., Zipfel, Bernhard, and Berger, Lee R. 2015. Identification of fossilized eggshells from the Taung hominin locality, Taung, Northwest Province, South Africa. Palaeontologia Electronica 18.1.11A: 1-16

palaeo-electronica.org/content/2015/1026-identification-of-fossil-eggs 
Keywords: Fossil eggs; faunal accumulators; avian; Taung; Plio-Pleistocene

\section{INTRODUCTION}

Plio-Pleistocene fossil-bearing localities of Taung (South Africa) became well known after Dart (1925) described the juvenile cranium of a hominin (i.e., the Taung Child) as the holotype of a new genus and species (Australopithecus africanus). Amongst the initial fossils described from Taung, there were numerous primate remains as well as other small mammals, reptiles and tortoises (Hrdlička, 1925; Dart, 1929). In addition, the presence of bird eggshells was mentioned by a number of researchers working on material from the Taung site (Hrdlička, 1925; Dart, 1929; Broom, 1934; Dart and Craig, 1959; Cooke, 1990; Berger and Clarke, 1995; McKee, 2001). Dart specifically mentioned a direct association of eggshells, the Taung Child, and its associated fauna (Dart and Craig, 1959, $p$. 4), but neither he, nor subsequent others studying material from Taung (Hrdlička, 1925; Dart, 1929; Broom, 1934; Dart and Craig, 1959; Cooke, 1990; Berger and Clarke, 1995; McKee, 2001) attempted to elucidate the taxonomic origin of the eggshells. The goal of the present study is to analyze the fossilized eggshells from Taung, in an effort to identify their possible avian affinity.

Because of their putative association with the hominin remains from Taung, speculation about the presence of avian taxa at Taung has received added attention. The significance of identifying avian taxa at Taung increased when Brain (1981) postulated that a bird might have been at least partly responsible for accumulating faunal remains at the site. He suggested that, while the majority of Taung faunal materials were probably collected by leopards (Panthera pardus), many smaller mammal specimens could have been collected by an avian source. Brain (1981) speculated that the eggshells found at Taung were most likely derived from Cape eagle owls (Bubo capensis), basing this assignation on their modern nesting practices in direct association with caves and the long held presumption that the fossil-bearing deposits were cave in-fills.

Berger and Clarke (1995), on the other hand, suggested that not only the smaller mammals, but in fact the majority of the faunal remains from Taung, including the Taung Child (U.W. 1-1) (Zipfel and Berger, 2009), were likely collected by a large raptor. Berger and Clarke (1995) based their hypothesis on indirect evidence. Specifically, they compared the Taung assemblage to faunal assemblages accumulated by three of the largest extant eagles found in South Africa: the martial eagle (Polemaetus bellicosus), the black eagle (Aquila verreauxii) and the crowned eagle (Stephanoaetus coronatus). Each of the three raptors are capable of carrying prey that are equivalent in body sizes to the estimated size of the Taung Child, as well as to other fauna found in association with it (Berger and Clarke, 1995). Purported taphonomic damage to the hominin cranium (i.e., talon puncture marks) further supported the possibility that a large raptor may have acted as an agent of accumulation at the site, specifically with regards to the hominin child (Berger, 2006; Berger and McGraw, 2007). Subsequent studies of crowned eagle predatory behaviour (Sanders et al., 2003; McGraw et al., 2006; Trapani et al., 2006) corroborate the possibility that a raptor may have acted as an agent of accumulation at Taung, at least to some degree. A recent study of Plio-Pleistocene cercopithecid fossils from sites on the Humpata Plateau (Angola) demonstrates the antiquity of raptor predation on primates, indicating that Taung may not have been an isolated incident and underscores the fact that researchers often dismiss raptor predation too readily as a selective force operating during primate evolution (Gilbert et al., 2009). These selective forces continue to operate amongst living primates who have developed specific alarm calls and antipredator behaviour in the presence of aerial predators (Struhsaker, 1967; Cheney and Seyfarth, 1981; Goodman, 1994; Csermely, 1996; Zuberbühler et al., 1997; Zuberbühler, 2001; Fichtel et al., 2005).

McKee (2001) proposed a non-raptor avian source for the fossilized eggshell fragments from Taung. He stated that " $[\mathrm{t}$ ]he fossil eggshells used as evidence for the raptor hypothesis come from the Dart deposits, and are too small to have come from a large eagle" (McKee, 2001, p. 107). On more than one occasion McKee has stated that the eggshells from Taung come from guinea fowl (McKee, 2001, 2010). Aside from this reference to guinea fowl attributions, or attempts to use guinea fowl attributions to refute the bird of prey hypothesis, implications for the presence of guinea fowl in the pink deposits at Taung have not been fully appreciated. Geologically the pink deposits (PCS) are landscape deposits that formed during times of 
tufa erosion, and are inter-bedded with phases of tufa deposition (Hopley et al., 2013).

Stable carbon isotope measurements of eggshell carbonate can be used to provide evidence of palaeodiets in the egg-layers. Plants following the $\mathrm{C}_{4}$ photosynthetic pathway (tropical grasses and sedges) have distinct carbon isotope compositions compared to those plants following the $\mathrm{C}_{3}$ pathway (trees, bushes, forbs). The mean $\delta^{13} \mathrm{C}$ for $\mathrm{C}_{3}$ plants today is about $-26 \%$, while the mean for $\mathrm{C}_{4}$ plants is $-12 \%$, and this distinction is reflected in the tissues of animal consumers depending on the proportions consumed within the diet with an offset specific to the organic or mineral phase being analysed (e.g., Lee-Thorp et al., 2007). The carbon isotope ratio of eggshell is expected to reflect the carbon isotope composition of the food consumed by the female bird, integrated over the 3-5 day period prior to egg-laying (Hobson, 1995). Despite a paucity of data on isotopic fractionation factors between $\delta^{13} C_{\text {diet }}$ and $\delta^{13} C_{\text {eggshell }}$ in different avian groups, species-specific effects seem to be small with values ranging from $16.2 \pm 0.5 \%$ for ostrich eggshell, Struthio camelus (von Schirnding et al., 1982; Johnson et al., 1998) and $15.6 \%$ for Japanese Quail, Coturnix japonica (Hobson, 1995). Schaffner and Swart (1991) observed a smaller fractionation factor (about 10 to $13 \%$ ) for seabirds that incorporated a high proportion of protein in their diet, suggesting that $\delta^{13} C_{\text {eggshell }}$ may be $>3$ $\%$ lighter in secondary consumers than in primary consumers given the same dietary $\delta^{13} \mathrm{C}$ value. These fractionation factors are similar to those observed for the carbonate component of mammalian tooth enamel (typically 12-14\%; Passey et al., 2005), enabling a direct comparison with the large body of literature on mammalian palaeodietary reconstruction using tooth enamel. Expected $\delta^{13} C_{\text {eggshell }}$ values for pure browser $\left(C_{3}\right.$ consumers) are about $-12 \%$ to $-14 \%$, while for pure grazers $\left(\mathrm{C}_{4}\right.$ consumers) they are about 0 to $-2 \%$ (Hobson, 1995; Johnson et al., 1998).

De Ruiter and colleagues (2010, p.132) suggested that if eagles did not "nest in the vicinity of caves, investigation of eagle involvement might produce spurious results." Thus, priority should be placed on identifying the source of the fossil eggshell fragments from Taung, since these may constitute reasonable evidence as to what avian nest(s) would have been in the vicinity of the deposits. The present study is an attempt at using direct evidence (i.e., the fossil eggshell fragments) to taxonomically identify avian taxa at Taung. We analyze microscopic structure and surface morphology of fossil and extant material, as well as carbon isotope signatures, in order to identify the avian taxon, or taxa, that were most likely responsible for the eggshell fragments recovered from deposits associated with the Dart Pinnacle, the presumed location of the hominin child cranium.

\section{MATERIAL AND METHODS}

Two partial fossilized eggs encased in breccia, T92-88 and T93-17 (Figure 1), were recovered from material collected at Taung, specifically the 'Dart Deposits', during the 1992 to 1993 excavations. Both eggshell fragments are curated at the University of the Witwatersrand. In order to exclude the possibility that the fossilized eggshells were chelonian in origin, we conducted X-Ray Diffraction (XRD) analysis on small aliquots of powdered eggshell. Chelonian eggshells are composed of aragonite, enabling them to be differentiated from the calcitic eggshells of other amniotes on the basis of their mineralogy (Hirsch, 1983). Aragonite is metastable and will be fully or partially replaced by calcite during diagenesis, although relics of the distinctive aragonite needles are usually observable in thin section or can be identified through XRD. No identifiable aragonite peaks were observed, effectively ruling out a chelonian origin for the fossil specimens.

In order to confirm the avian origin, we used comparative extant material from the Johannesburg Zoo and the Ditsong National Museum of Natural History (Pretoria), including mostly African species as well as non-indigenous species with eggs of an approximately similar size. African species included black eagle, giant eagle owl (Bubo lacteus), Cape eagle owl, spotted eagle owl (Bubo africanus), Egyptian goose (Alopochen aegyptiacus), fulvous whistling duck (Dendrocygna bicolour), flamingo (Phoenicopterus roseus), marabou stork (Leptoptilos crumeniferus), lappet-faced vulture (Torgos tracheliotus) and helmeted guinea fowl (Numida meleagris). Eurasian eagle owl (Bubo bubo) and snowy owl (Bubo scandiacus) were included in the sample as a means of validating our methods of comparison. These latter two birds have eggs of similar sizes and shapes to the African birds in the sample, but their present range and migratory patterns make it highly unlikely that they could have been the source of the Taung eggshell fragments. If either of these birds is identified as a likely source, then the protocol for identification can be considered insufficiently robust. 


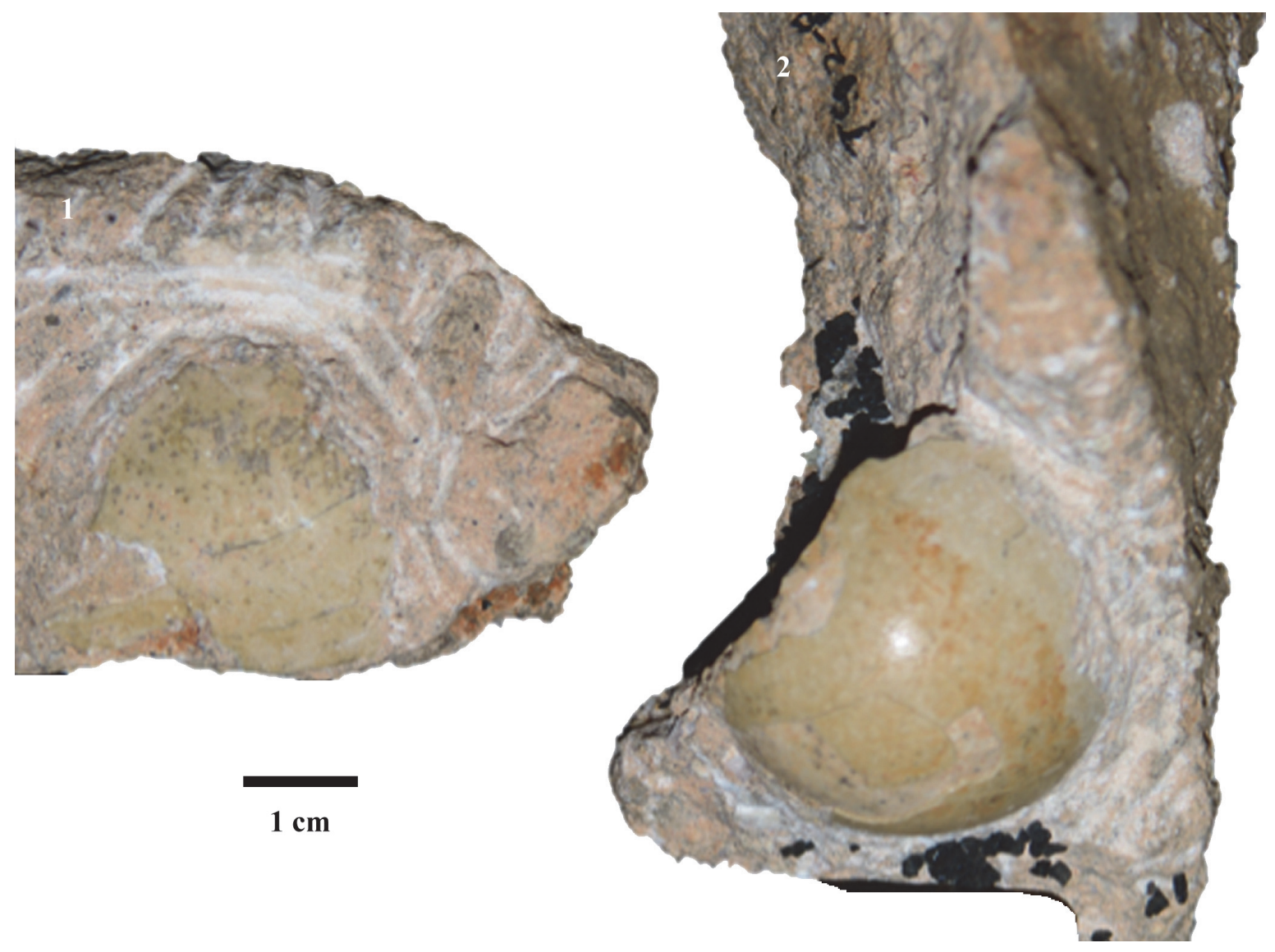

FIGURE 1. Fossil eggs from Taung, T92-88 on the right and T93-17 on the left.

All of the selected taxa produce eggs that visually and metrically approximate the size and shape range encompassing the Taung fossilized eggshell specimens. The selected species span several avian Orders, increasing the chance of taxonomic attribution. Additional data from Winterbottom (1971) and Tarboton $(2001,2011)$ were used to identify Order, Family and species-specific traits and variation within these and other species. It must be acknowledged that southern Africa may have been home to larger raptors than exist today. The Malagasy Crowned eagle (Stephanoaetus mahery) and Malagasy Aquila eagles went extinct from Madagascar in the Holocene (Goodman, 1994; Goodman and Rakotozafy, 1995). Thus, it is possible that even larger raptors than exist today operated in the Plio-Pleistocene of southern Africa. In this case, it would be unclear whether their form or overall size would resemble the form and overall size of a modern raptor egg form. It is worth noting that both Aquila sp. and Gyps sp. have been identified amongst the Taung avian material from previous excavations (Baker, 2010).
The first phase of comparative investigations involved analysing surface morphologies. All surface analyses were performed on an Olympus SZX 9 microscope fitted with a 3.34 megapixel Nikon cool pix 990 digital camera. All specimens were photographed at 6.3X (Figure 2), 12.5X (Figure 3) and 57X (Figure 4) magnifications. Shell morphology was examined noting differences in pinprick pore size, shape and distribution following the protocol established by Harrison and Msuya (2005) on struthionid eggshells. As illustrated in Figures 2, 3 and 4 , variation in shell morphology is more apparent as magnification increases. This increase is particularly noteworthy between $6.3 \mathrm{X}$ and $12.5 \mathrm{X}$ magnifications. The first phase of the analysis excluded all but a handful of specimens. Further investigation of microscopic structure was attempted using scanning electron microscopy (SEM).

We imaged the fossil eggshell fragments with a JSM-6480 variable pressure Scanning Electron Microscope (SEM). Under vacuum, freshly cut surfaces were analysed by tilting them on the microscope mounting plate so these regions could be 


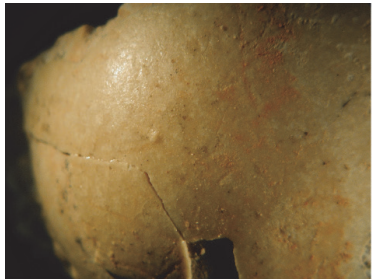

T 92-88

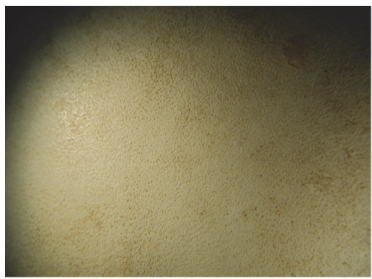

Marabou stork

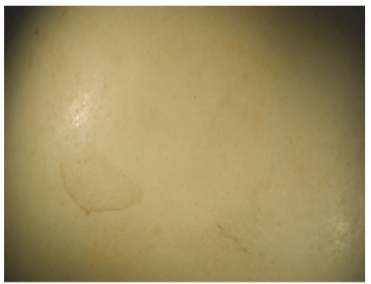

Fulvous whistling duck

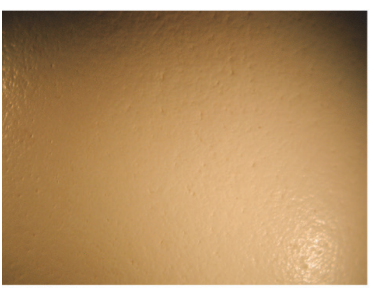

Giant eagle owl

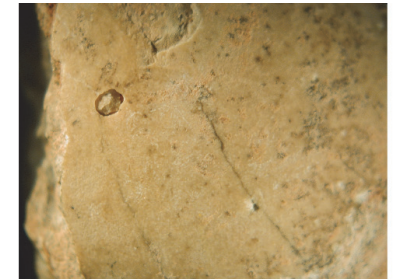

T 93-17

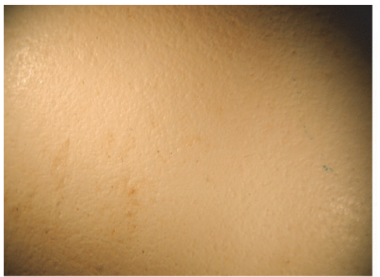

Eurasian eagle owl

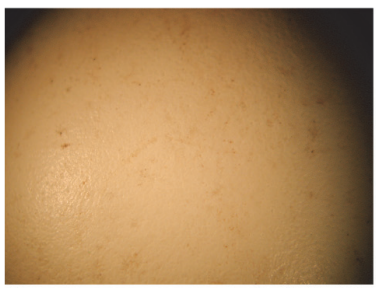

Snowy owl

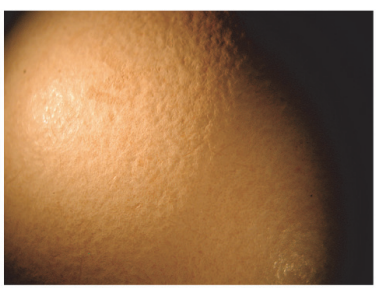

Helmeted guinea fowl

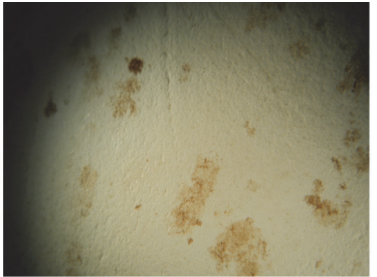

Lappet-faced vulture

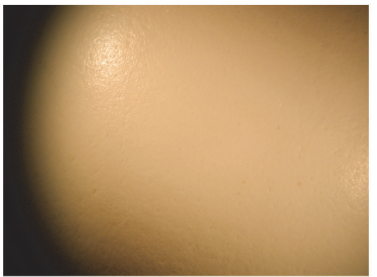

Spotted eagle owl

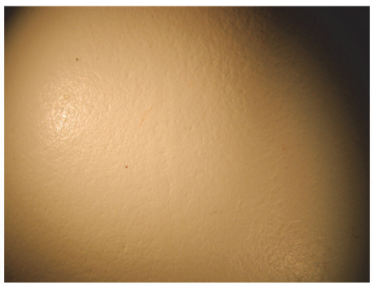

Cape eagle owl

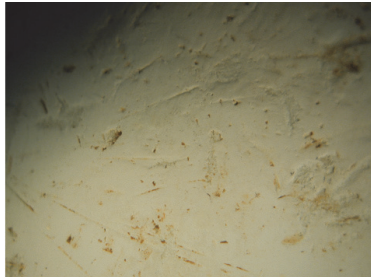

Flamingo

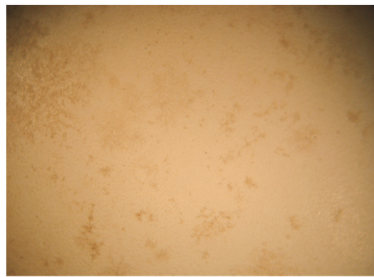

Egyptian goose

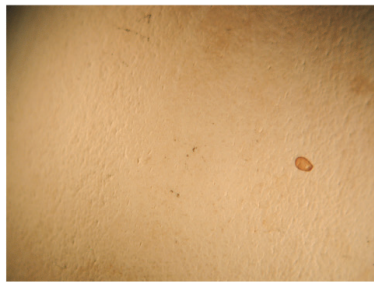

Black eagle

FIGURE 2. All specimens, both extant eggs and fossil eggshells, showing surface morphology at $6.3 \mathrm{X}$ magnification.

scanned by the beam of electrons (resolution of 3.0 $\mathrm{nm})$. In order to keep the samples pristine, we did not coat the samples in conductive material before hand; this has caused some charging in our images due to build up of electrons on the surface of the samples; this affect was minimised by using a relatively low voltage of $3 \mathrm{kV}$. We have varied the magnification of the SEM in order to identify structures at all scales on the surface of the samples.

The second phase of comparative investigations- a surface curvature analysis of the eggshell fragments- involved fitting partial fossilized eggshells to whole eggs. Computerized tomography (CT) was used to acquire digital images of both the fossil eggshell fragments and extant eggs. Fossil specimens were scanned at Helen Joseph Hospital, Johannesburg, South Africa, using a Philips Brilliance 16 CT scanner (Philips Healthcare,
Andover, MA) with the following parameters: $1 \mathrm{~mm}$ slice thickness, $0.2 \mathrm{~mm}$ or $0.5 \mathrm{~mm}$ reconstruction increment, an 83 or $65 \mathrm{~mm}$ field of view (FOV), a $512 \times 512$ pixel matrix, $\mathrm{kV}$ of 120 , tube current of 254 or 317 and an ultra high reconstruction filter. Extant specimens were scanned at Charlotte Maxeke Johannesburg Academic Hospital, Johannesburg, South Africa, using a Siemens Biograph 40 scanner (Siemens Medical Solutions USA, Inc., Malvern, PA) with the following parameters: 0.6 $\mathrm{mm}$ slice thickness, $0.3 \mathrm{~mm}$ reconstruction increment (except for the Cape eagle owl for which 0.6 $\mathrm{mm}$ was used), a $108 \mathrm{~mm}$ FOV, a 512 x 512 pixel matrix, kV of 120 , tube current of 200 , and an H60s (very sharp) reconstruction filter.

All images generated from CT scanning were saved as DICOM files for subsequent analysis. From the DICOM image stack corresponding to an 


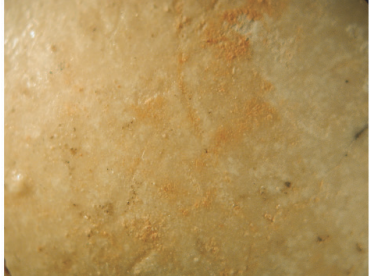

T 92-88

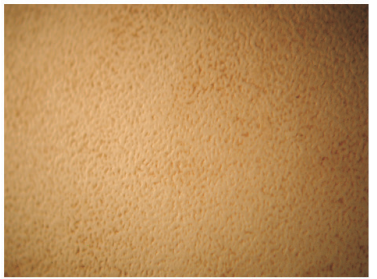

Marabou stork

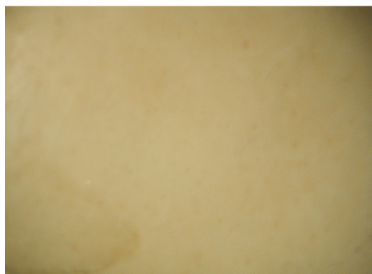

Fulvous whistling duck

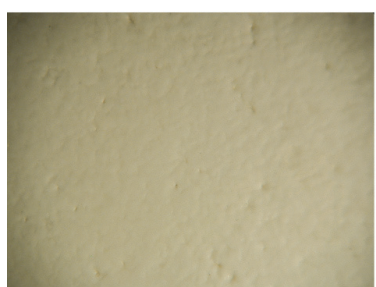

Giant eagle owl

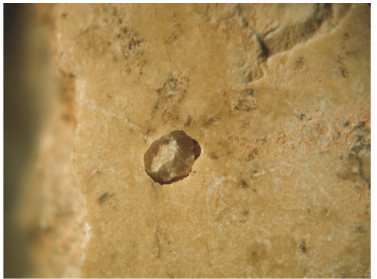

T 93-17

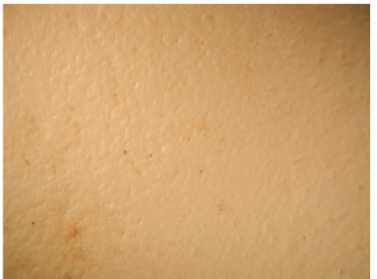

Eurasian eagle owl

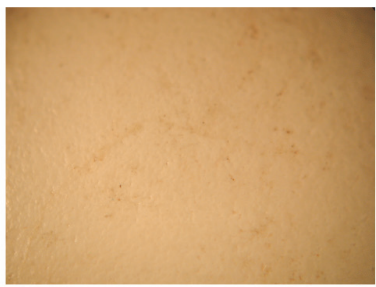

Snowy owl

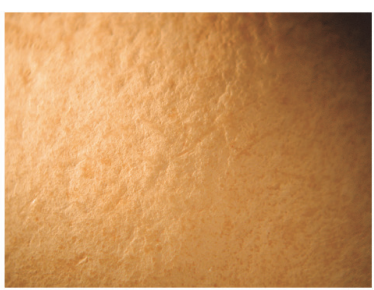

Helmeted guinea fowl
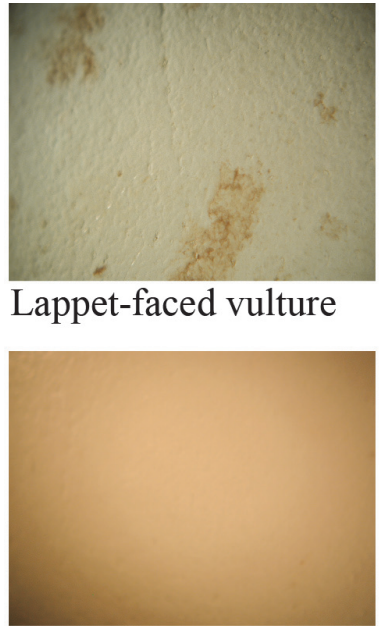

Spotted eagle owl

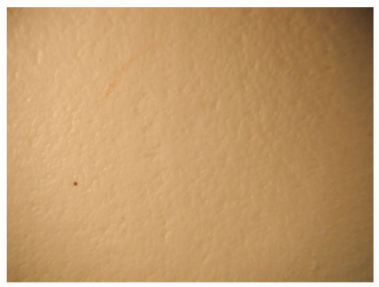

Cape eagle owl

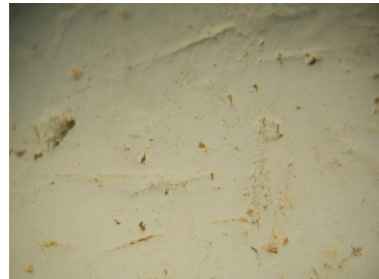

Flamingo

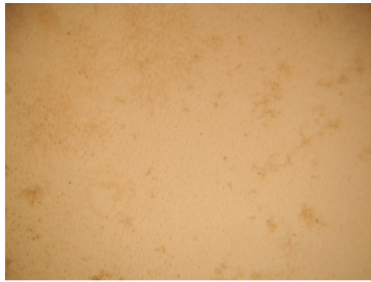

Egyptian goose

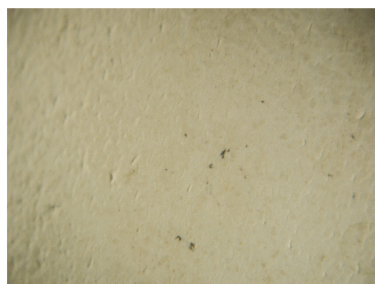

Black eagle

FIGURE 3. All specimens, both extant eggs and fossil eggshells, showing surface morphology at $12.5 \mathrm{X}$ magnification.

object, fossils in matrix or complete extant eggs were segmented using Avizo 6.1 (Visualization Sciences Group, Mérignac, France). For the fossils, this involved digitally separating eggshell fragments from surrounding matrix (Figure 5). Material density contrast between fossil eggshell fragments and surrounding stone in the acquired image stacks was insufficient to permit the use of automated segmentation methods. Rather, we used the LabelField module in Avizo 6.1, going through the image stack in three orthogonal directions and manually differentiating fossil eggshell from matrix, a technique that provided excellent results for fossil material from the Malapa site in South Africa (Val et al., 2011). Shell thickness was consistently overestimated during manual segmentation, but in a conservative manner, since the purpose of this analysis was to fit surface curvatures of the fossilized fragments to surface curvatures of the extant complete eggs. Differing thicknesses of shell fragments would not affect quantifications of surface curvature. Using the exposed external portion of fossil eggshell fragments as a guide, it was possible to approximate curvature of the embedded inner surface when it was not distinct in DICOM files, thus conservatively creating a relatively uniformly thick fossilized eggshell fragment (Figure 5). In our opinion, ignoring localized thinning of the shell with this protocol would not have altered surface curvature fits.

After generating renderings of fossil fragments and extant eggshells, each fossil fragment was manually fit to extant eggs using the SurfaceView module in Avizo 6.1 (Figure 6). Each fossil eggshell 


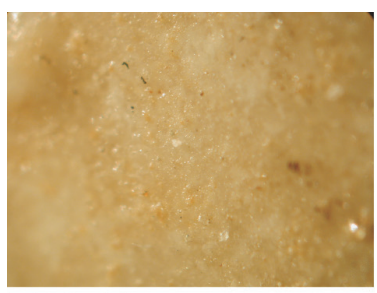

T 92-88

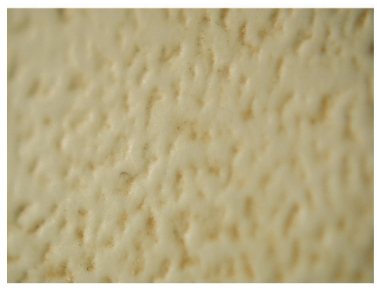

Marabou stork

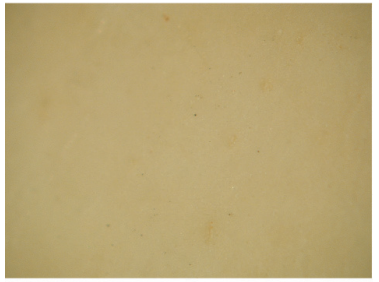

Fulvous whistling duck

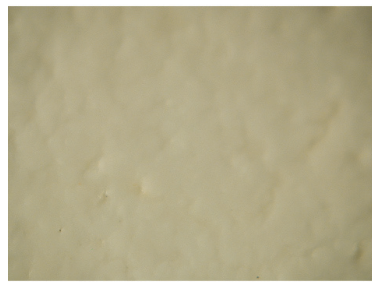

Giant eagle owl

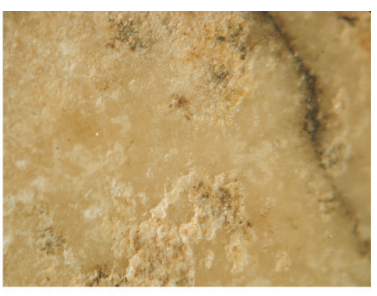

T 93-17
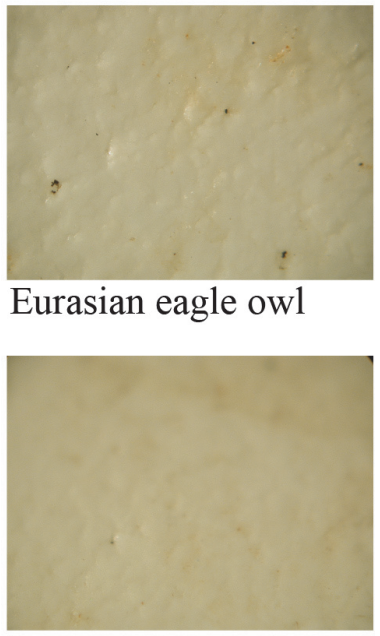

Snowy owl

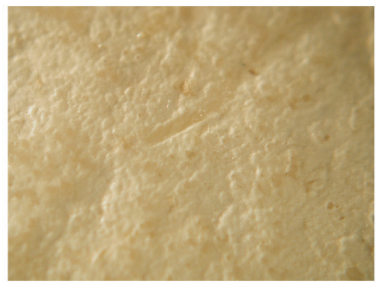

Helmeted guinea fowl

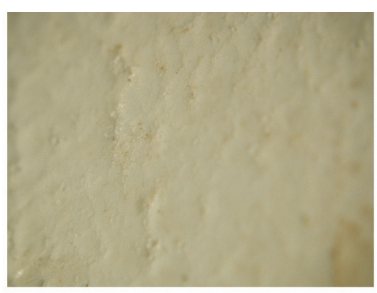

Lappet-faced vulture

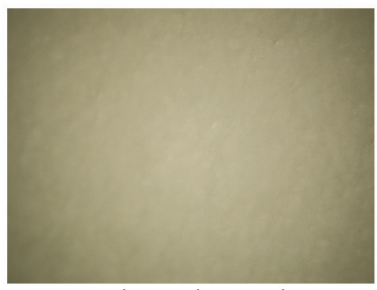

Spotted eagle owl

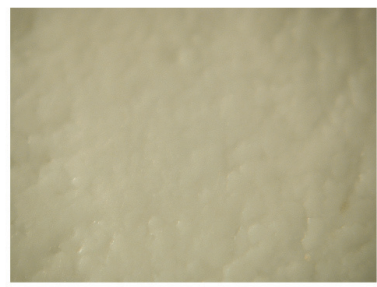

Cape eagle owl

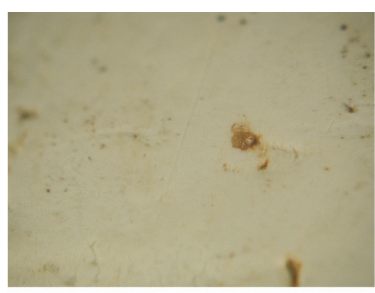

Flamingo

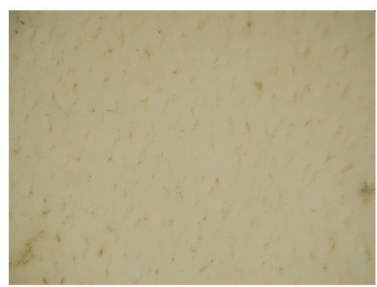

Egyptian goose

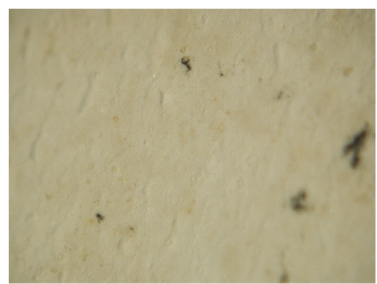

Black eagle

FIGURE 4. All specimens, both extant eggs and fossil eggshells, showing surface morphology at 57X magnification.

fragment was fit to each extant egg in multiple locations since various surface curvatures are represented within a single eggshell (e.g., at the apical and blunt poles or at the equatorial region). Thus, the initial step of the fitting procedure involved manual alignment of the two surfaces. Subsequently, more precise alignment techniques were available using the AlignSurface module. This essentially consisted of a series of rotations of a specified 3D model object (i.e., a fossil eggshell fragment) performed in order to fit it to a 3D reference object (i.e., a complete extant egg). These rotations sought to converge on a minimization of the root mean square (RMS) between points representing the model and reference object surfaces. Quantification of the minimum Euclidian distances between the surfaces is similar to a Procrustes method, except that scale (i.e., overall size) was not altered in the alignments. The fit of model and reference object surfaces was quantified by an RMS value after a number of iterations was reached that achieved a specified change in the RMS value (i.e., 0.001 was chosen arbitrarily as the value). The RMS values, therefore, represent how well the two rendered surfaces can be aligned using only surface shapes (i.e., curvatures). The surface fitting procedure was performed by one author (KC) who was not given a priori information on the bird species associated with each extant egg. This created a blind protocol for matching surface curvatures of fossil eggshell fragments and extant eggs. After identifying the minimum RMS value associated with a corresponding iterative change in RMS value below 0.001 , the first fitting 


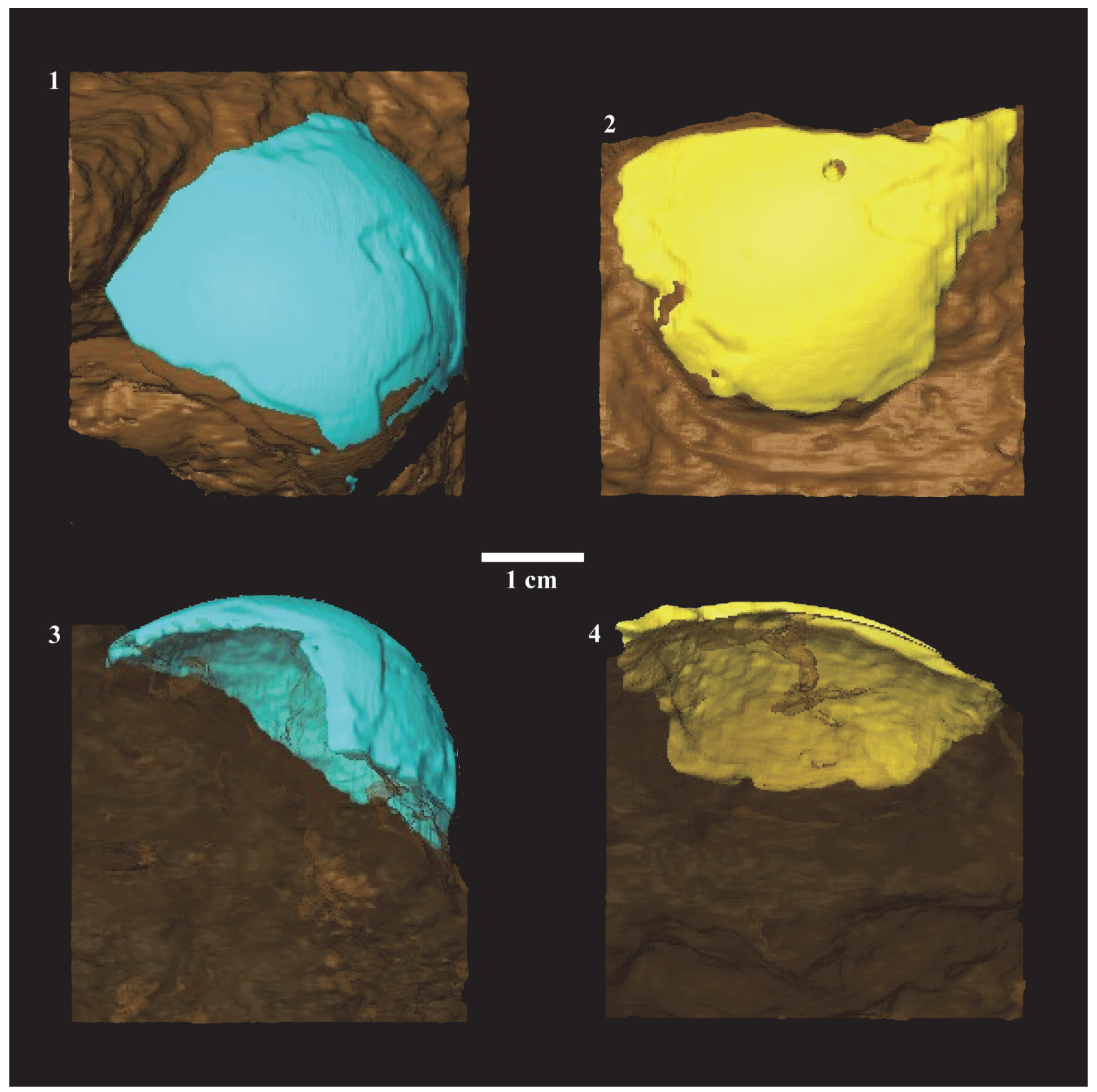

FIGURE 5. Renderings of fossil eggshell fragments embedded in matrix (1-2) and indication of the internal boundary between eggshell and matrix (3-4). Images 1 and 3 are fossil eggshell fragment T92-88, and images 2 and 4 are fossil eggshell fragment T93-17. Note the relatively consistent thickness at the edges and how this maintained surface curvatures indicated by the external surfaces.

procedure was completed and a second fitting procedure was undertaken. The second procedure was a duplication of the first procedure, except for the fact that the 3D model object was allowed to change scale (i.e., overall size) in addition to rotating and translating.

A small fragment $\left(<3 \mathrm{~mm}^{2}\right)$ of T93-17 and T92-88 was collected for isotopic analysis. For comparative purposes, four other fossil eggshell fragments from the PCS deposit at Taung were also collected. The PCS deposit is a pink landscape deposit, which runs though both the Dart and Hrdlička Pinnacles and beyond (Hopley et al., 2013). All eggshell fragments were broken into two aliquots, cleaned of matrix using a diamond-tipped drill, and crushed using a pestle and mortar. Samples of the carbonate matrix were also collected for stable isotope analysis to serve as a control for diagenetic alteration and matrix contamination of the fossil eggshell fragments. Powdered carbonate 


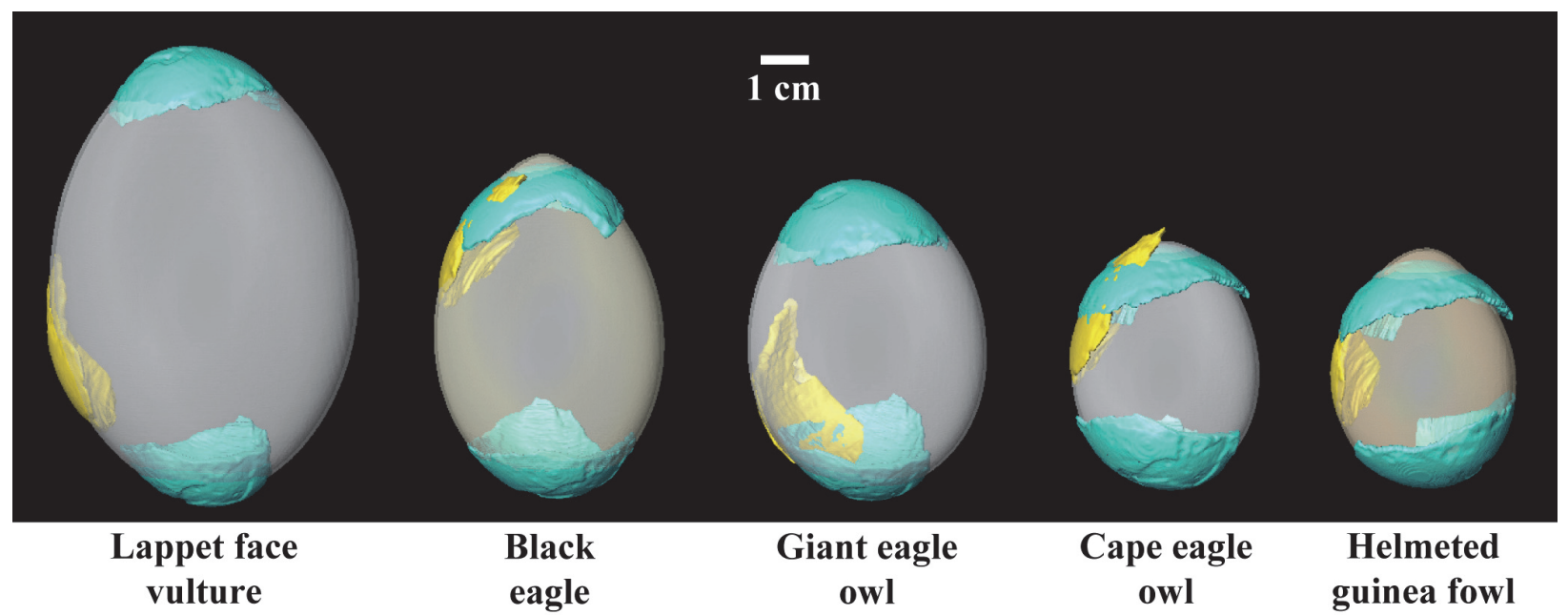

FIGURE 6. Fossil eggshell fragments T92-88 (blue) and T93-17 (yellow) fit to eggs from five extant birds. Fits depicted visually in the figure (rigidly constrained size) correspond to root mean square (RMS) values reported in Table 2 . Note that visual correspondence supports quantification of RMS values in that fossil eggshell fragment T92-88 fits best with the blunt pole of the extant guinea fowl egg. Extant black eagle (blunt pole) and giant eagle owl (apical pole) eggs provide the next closest, but still worse fits. Fossil eggshell fragment T93-17 fits best with the equatorial region of the black eagle egg. The extant guinea fowl egg provides the next closest fit for fossil eggshell fragment T93-17.

samples $(\sim 150 \mu \mathrm{g})$ were analyzed for carbon and oxygen isotopes $\left(\delta^{13} \mathrm{C}, \delta^{18} \mathrm{O}\right)$ using continuous flow isotope ratio mass spectrometry. All data are reported in the standard delta notation relative to VPDB. Reproducibility of an internal standard was $\pm 0.1 \%$ for both carbon and oxygen. Birds often consume limestone grit as a source of calcium to improve shell strength; the consumed carbonate is dissolved within the stomach and does not contribute carbon to the eggshell (von Schirnding et al., 1982).

\section{RESULTS}

Surfaces of both fossilized eggshell specimens, T92-88 and T93-17, retain numerous pinprick pores that are visible at microscopic levels. The majority of pores are roughly round in shape, while some elliptical pores are observable and scattered intermittently. The interior portions of the fragments are filled with breccia indicating that the eggs were broken prior to their deposition. One fragment (T92-88) exhibits further evidence for this since a portion of the shell has sloughed off, most probably after recovery, exposing the calcified sediment that maintains the smooth curvature of the inner surface of the eggshell. The exposed shell from T92-88 measures approximately $40.31 \mathrm{~mm} x$ $34.41 \mathrm{~mm}$ with an average shell thickness of 0.84 $\mathrm{mm}$, but CT imaging indicates that there is slightly more eggshell embedded entirely in the matrix.
Regardless of the avian taxon of origin, surface curvature of this specimen is consistent with an area near and including the blunt pole, or near and including the apical pole. The exposed shell of the other fragment (T93-17) measures $32.84 \mathrm{~mm} x$ $28.63 \mathrm{~mm}$ with an average shell thickness of 0.49 $\mathrm{mm}$. Regardless of the avian taxon of origin, surface curvature of this specimen is consistent with an origin near the equatorial region between blunt and apical poles. For reference the eggshell thicknesses of the extant black eagles ranged from 2.6 $\mathrm{mm}$ at the apical pole to $0.53 \mathrm{~mm}$ at the widest portion of the egg to $2.5 \mathrm{~mm}$ at the blunt pole. The guinea fowl used in this study ranged from $2.1 \mathrm{~mm}$ at the apical pole to $0.71 \mathrm{~mm}$ at the widest point of the egg to $2.3 \mathrm{~mm}$ at the blunt pole.

SEM work proved to be inconclusive. Internal structure of the fossilized eggshell fragments, such as form of the mammillary layer and squamatic zone, was not retained (see Figure 7). If such structure were retained, however, comparison of individual layers would be a useful endeavour since modern Avian taxa exhibit characteristic differences in these layers (Mikhailov, 1997). Future investigations of fossilized eggshells should still consider this approach, despite its uninformative contribution in the present study.

\section{Surface Morphology Diagnosis}

Visual differences in surface morphology can be observed at various levels of microscopy. Mor- 


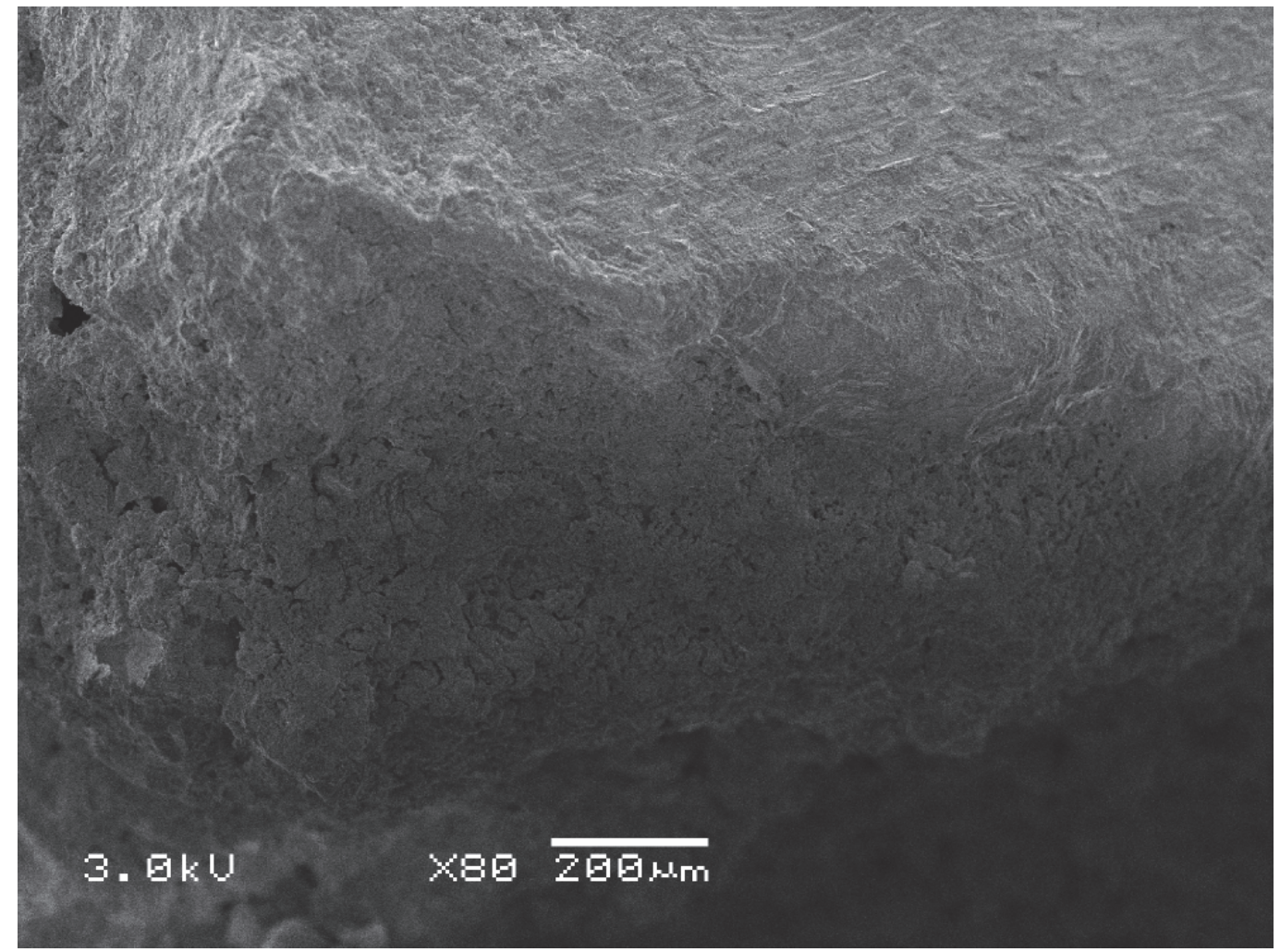

FIGURE 7. Representative SEM results from one (TDES 3) of the fossil eggshells.

phological differences such as the shell surface being smooth or rough, shape of pores (round or oblong, and size) and distribution of pores (sparse or dense) can all be used to rule out various extant specimens. At 6.3X magnification, Egyptian goose, fulvous whistling duck and flamingo were eliminated from the list of possible sources due to the absence of pores on their respective surfaces. Examination of surface morphology under $12.5 \mathrm{X}$ magnification excluded the marabou stork since morphology of the pores on both Taung specimens did not resemble the distinct surface morphology of marabou stork. Examination of eggs at 57X magnification corroborated the elimination of the previously mentioned specimens, but could not rule out the remaining specimens (see Figures 2, 3 and 4).

\section{Surface Curvature Analysis}

Specimen T92-88 has a surface curvature that best fits the surface curvature of a helmeted guinea fowl egg (three times), or a giant eagle owl (one time) (Table 1). When overall size of the surface is held constant, surface curvature of this specimen best fits surface curvature of a giant eagle owl apical pole (0.79) or a helmeted guinea fowl blunt pole $(0.70)$ (Table 1$)$. When overall size of the surface is allowed to change, best fits are either with a hel- meted guinea fowl apical pole (0.32) or helmeted guinea fowl blunt pole $(0.68)$ (Table 1$)$. It is important to note that a substantial size change was necessary in arriving at the apical pole fit (i.e., size change is proportionate to the number of iterations in Table 1).

Specimen T93-17 also does not unanimously match a single extant taxon. When overall size of the surface is held constant, surface curvature of specimen T93-17 best fits surface curvature of a black eagle egg (0.67) (Table 1). While the helmeted guinea fowl egg has the second best surface curvature fit when size is held constant (0.75), it exhibits the best fit when size is allowed to change (0.56) (Table 1). This best fit pattern remains even when comparing the specimen to several black eagle eggs (Table 2 and Figure 8 ). Four of the six black eagle eggs exhibit better surface curvature fits than that of the helmeted guinea fowl egg when size is held constant, while all six black eagle eggs exhibit worse surface curvature fits than the helmeted guinea fowl egg when size is allowed to change (Table 2). Interestingly, the lone black eagle egg (Figure 8.1: JHB Zoo) that does not conform to this pattern was infertile, and clearly exhibits a different shape from any of the other illustrated black eagle eggs (Figure 8). Similarly 
TABLE 1. Fitting surfaces of fossil eggshell fragments to intact extant eggshells using root mean square values.

\begin{tabular}{lcccccc}
\hline $\begin{array}{c}\text { Fossil egg } \\
\text { fragment }\end{array}$ & $\begin{array}{c}\text { Egg } \\
\text { location }\end{array}$ & Lappet face vulture & Black eagle(a) & Giant eagle owl & Cape eagle owl & $\begin{array}{c}\text { Helmeted guinea } \\
\text { fowl(b) }\end{array}$ \\
\hline T92-88(c) & Apical & $0.86(7)$ & $1.00(7)$ & $0.79^{*}(8)$ & $1.00(9)$ & $1.20(26)$ \\
& pole & {$[0.86(2)]$} & {$[0.75(130)]$} & {$[0.79(2)]$} & {$[0.84(38)]$} & {$\left[0.32^{*}(254)\right]$} \\
\cline { 2 - 7 } & Blunt & $1.23(7)$ & $1.19(6)$ & $1.12(6)$ & $0.82(8)$ & $0.70^{*}(19)$ \\
& pole & {$[0.87(141)]$} & {$[0.79(152)]$} & {$[0.85(75)]$} & {$[0.79(15)]$} & {$\left[0.68^{*}(16)\right]$} \\
\hline T93-17 & Side & $0.91(5)$ & $0.67^{*}(7)$ & $0.81(6)$ & $0.89(95)$ & $0.75(59)$ \\
& & {$[0.91(2)]$} & {$[0.67(2)]$} & {$[0.80(7)]$} & {$[0.71(45)]$} & {$\left[0.56^{*}(2)\right]$} \\
\hline
\end{tabular}

Within cells, top lines refer to rigid fits, where only rotations and translations were used, while bottom lines correspond to rigid and scaled fits, where both the size of the fossil fragment and rotations/translations were used to arrive at the best 'fit'. Rigid and scaled fits were performed after arriving at the best 'fit' using rigid fits (i.e., rotations and translations only). (a)Values are best-fitting black eagle examples from Table 2: TM 33879, TM42505, TM43471, and TM43505 for fragment T92-88; TM 088 for fragment T93-17. (b)Values are best-fitting guinea fowl examples from Table 3: eggs 2, 4, and 5 for fragment T92-88; egg 5 for fragment T93-17. (c)Fragment includes either the apical or blunt pole so both were assessed. *best match in surface curvature fitting. Number of iterations to achieve an RMS change less than 0.001 are reported in parentheses for each line.

TABLE 2. Fitting surfaces of fossil eggshell fragments to intact extant Black eagle eggshells using root mean square values.

\begin{tabular}{lccccccc}
\hline $\begin{array}{c}\text { Fossil egg } \\
\text { fragment }\end{array}$ & $\begin{array}{c}\text { Egg } \\
\text { location }\end{array}$ & $\begin{array}{c}\text { Black eagle } \\
(\text { JHB Zoo)(a) }\end{array}$ & $\begin{array}{c}\text { Black eagle } \\
(\text { TM 088) }\end{array}$ & $\begin{array}{c}\text { Black eagle } \\
\text { (TM 33879) }\end{array}$ & $\begin{array}{c}\text { Black eagle } \\
\text { (TM 42505) }\end{array}$ & $\begin{array}{c}\text { Black eagle } \\
\text { (TM 43471) }\end{array}$ & $\begin{array}{c}\text { Black eagle } \\
(\text { TM 43505) }\end{array}$ \\
\hline T92-88(b) & Apical & $1.04(11)$ & $1.06(6)$ & $1.00(12)$ & $1.05(96)$ & $1.00^{*}(7)$ & $1.11(7)$ \\
& pole & {$[0.70(119)]$} & {$[0.78(146)]$} & {$[0.79(95)]$} & {$\left[0.75^{*}(130)\right]$} & {$[0.81(98)]$} & {$[0.81(123)]$} \\
\cline { 2 - 8 } & Blunt & $0.83(8)$ & $1.26(7)$ & $1.24(6)$ & $1.37(7)$ & $1.38(7)$ & $1.19^{*}(6)$ \\
& pole & {$[0.79(5)]$} & {$[0.82(152)]$} & {$\left[0.77^{*}(152)\right]$} & {$[0.79(218)]$} & {$[0.84(143)]$} & {$[0.83(141)]$} \\
\hline T93-17 & Side & $0.88(5)$ & $0.67^{*}(7)$ & $0.71(6)$ & $0.68(7)$ & $0.70(6)$ & $0.76(19)$ \\
& & {$[0.88(2)]$} & {$\left[0.67^{*}(2)\right]$} & {$[0.71(2)]$} & {$[0.68(5)]$} & {$[0.70(2)]$} & {$[0.75(8)]$} \\
\hline
\end{tabular}

Within cells, top lines refers to rigid fits, where only rotations and translations were used, while bottom lines correspond to rigid and scaled fits, where both the size of the fossil fragment and rotations/translations were used to arrive at the best 'fit'. Rigid and scaled fits were performed after arriving at the best 'fit' using rigid fits (i.e., rotations and translations only). (a)Egg from an infertile zoo individual. (b)Fragment includes either the apical or blunt pole so both were assessed. *best match in surface curvature fitting amongst nonzoo specimens. Number of iterations to achieve an RMS change less than 0.001 are reported in parentheses.

with helmeted guinea fowl eggs, the results were fairly constant when more than one egg was analysed (Table 3 and Figure 8).

\section{Stable Isotope Analysis}

All eggshell fragments analysed have $\delta^{13} \mathrm{C}$ and $\delta^{180} \mathrm{O}$ values that differ from the PCS calcrete matrix, indicating that a distinct eggshell signal has been retrieved, and that diagenetic alteration was minimal (Table 4). Replicate samples are tightly clustered and enable a minimum of three individuals to be identified from the four fragments analysed (see Figure 9). TDES 2 and TDES 3 have overlapping isotope values suggesting that they could be fragments of the same egg or same clutch of eggs. Eggshell $\delta^{13} \mathrm{C}$ values range from $-11.85 \%$ to $-0.45 \%$, consistent with a range of diets from pure $\mathrm{C}_{3} / \mathrm{C}_{3}$ dominated to pure $\mathrm{C}_{4}$ (taking the uncertainty of species specific diet-eggshell fractionation factors into account). T92-88 and the three other eggshell individuals all have a $\mathrm{C}_{4}$ dominated diet and an overlapping dietary ecology, making it a distinct possibility that they all belong to the same avian species. However, T93-17 has a $\mathrm{C}_{3}$ dominated diet and a distinct dietary behaviour indicating that it belongs to a different avian species than the other fragments.

\section{DISCUSSION AND CONCLUSION}

By analyzing fossilized eggshell fragments from Taung using multiple lines of investigation, we provide further evidence for the presence of specific avian taxa at Taung during the Plio-Pleistocene. Fossilized eggshell fragments were compared to hypothetically similarly-sized eggs from a number of extant bird species, including 

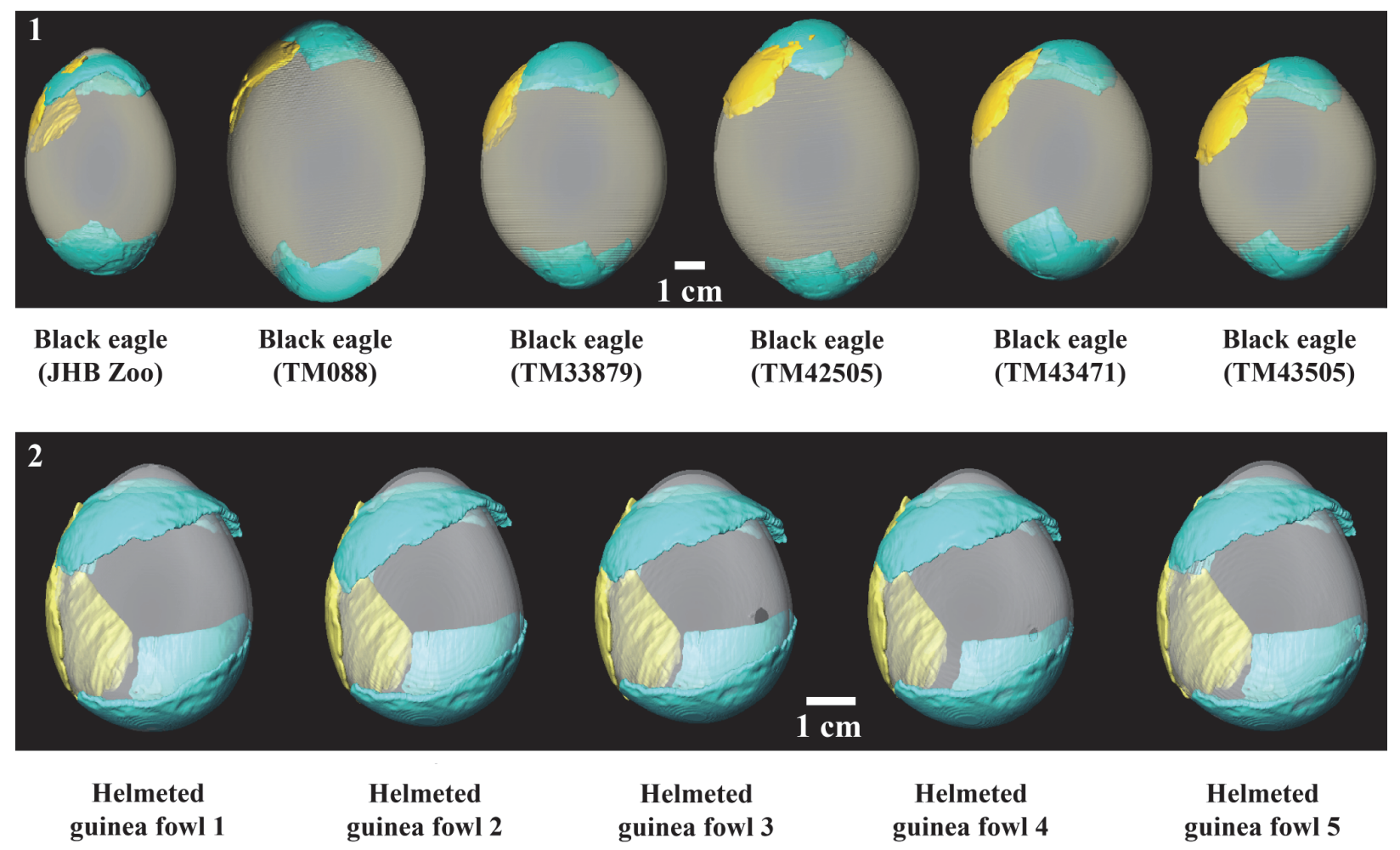

Helmeted

FIGURE 8. (1) Fossilized eggshell fragments T92-88 (blue) and T93-17 (yellow) indicating best fit to the same black eagle egg as illustrated in Figure 6, plus six additional black eagle eggs. Note despite intraspecific variability in egg shape, the fits are quite similar (also see Table 3). This suggests even accounting for intraspecific variability in egg shape Results in Table 2 should be robust. (2) Fossil eggshell fragments T92-88 (blue) and T93-17 (yellow) indicating best fit to the same guinea fowl egg as illustrated in Figure 6 (far left), plus four additional guinea fowl eggs. Note that despite intraspecific variability in egg shape, the fits are quite consistent (also see Table 3 ). This suggests that even accounting for intraspecific variability in egg shape results of the surface curvature analyses are robust.

geese, owls, eagles, guinea fowl and vultures. In documenting a combination of microscopic and macroscopic morphological differences between the eggs of various avian species and the Taung fossilized eggshell fragments, several taxa were systematically eliminated as potential sources of the fossilized eggshell fragments. Examination of surface morphology excluded all but four potential types of birds that may have been the source of the two fossilized eggshell fragments from Taung. Ultimately, two most probable avian sources (i.e., Numididae [helmeted guinea fowl] and Aquilinae [black eagle]) were identified as responsible for laying these eggs. Since it is generally known that modern eggshell thickness can be influenced by environmental factors we chose to report shell thickness but not use it as a diagnostic tool in this study.

Surface curvature analysis alone suggested that a helmeted guinea fowl egg was the most likely source for one fragment (T92-88), while a helmeted guinea fowl egg or a black eagle egg appeared equally likely as the source for the other fragment (T93-17), depending on whether overall size was constrained (Table 1). The issue of whether it is reasonable to constrain overall size of the fossilized eggshell fragments is not trivial. Southern Africa may have been home to larger raptors than exist today. The Malagasy Crowned eagle (Stephanoaetus mahery) and Malagasy Aquila eagles went extinct from Madagascar in the Holocene (Goodman, 1994; Goodman and Rakotozafy, 1995). It is possible that larger raptors than exist today operated in the Plio-Pleistocene of southern Africa. In this case, it is unclear whether the form of their eggs (or their overall size) would resemble modern raptor egg form (or overall size).

Of the three bird forms previously hypothesized to have laid eggs at Taung, owls in general are less likely than the other two due to their exclusion through the surface curvature analysis. Moreover, to our knowledge, the only reported cases of 
TABLE 3. Fitting surfaces of fossil eggshell fragments to intact extant Guinea fowl eggshells using root mean square values.

\begin{tabular}{lcccccc}
\hline $\begin{array}{c}\text { Fossil egg } \\
\text { fragment }\end{array}$ & $\begin{array}{c}\text { Egg } \\
\text { location }\end{array}$ & Guinea fowl 1 & Guinea fowl 2 & Guinea fowl 3 & Guinea fowl 4 & Guinea fowl 5 \\
\hline T92-88(a) & Apical & $1.30(18)$ & $1.37(46)$ & $1.40(20)$ & $1.20^{*}(26)$ & $1.34(25)$ \\
& pole & {$[0.39(200)]$} & {$[0.32(206)]$} & {$[0.35(204)]$} & {$[0.34(251)]$} & {$\left[0.32^{*}(254)\right]$} \\
\cline { 2 - 7 } & Blunt & $0.80(17)$ & $0.72(21)$ & $0.72(18)$ & $0.70^{*}(19)$ & $0.75(23)$ \\
& pole & {$[0.79(5)]$} & {$\left[0.68^{*}(16)\right]$} & {$[0.70(11)]$} & {$[0.70(5)]$} & {$[0.75(4)]$} \\
\hline T93-17 & Side & $0.84(18)$ & $0.84(17)$ & $0.84(33)$ & $0.82(16)$ & $0.75^{*}(59)$ \\
& & {$[0.58(63)]$} & {$[0.59(61)]$} & {$[0.60(60)]$} & {$[0.57(53)]$} & {$\left[0.56^{*}(2)\right]$} \\
\hline
\end{tabular}

Within cells, top lines refers to rigid fits, where only rotations and translations were used, while bottom lines correspond to rigid and scaled fits, where both the size of the fossil fragment and rotations/translations were used to arrive at the best 'fit'. Rigid and scaled fits were performed after arriving at the best 'fit' using rigid fits (i.e., rotations and translations only). (a)Fragment includes either the apical or blunt pole so both were assessed. *best match in surface curvature fitting. Number of iterations to achieve an RMS change less than 0.001 are reported in parentheses.

TABLE 4. Carbon and oxygen isotope data for fossil eggshells, eggshell fragments and sediment all collected from the Plio-Pleistocene PCS calcrete exposed at the base of the Dart Pinnacle, Taung.

\begin{tabular}{|c|c|c|c|}
\hline Material & Sample ID & $\mathbf{\delta}^{13} \mathbf{C}$ & $\mathbf{\delta}^{\mathbf{1 8}} \mathbf{0}$ \\
\hline Eggshell Fragment & T93-17 & -11.56 & -5.41 \\
\hline Eggshell Fragment & T93-17 & -11.85 & -5.44 \\
\hline Eggshell Fragment & T92-88 & -0.57 & -7.51 \\
\hline Eggshell Fragment & T92-88 & -0.45 & -7.54 \\
\hline Eggshell Fragment & TDES 1 & -4.65 & -0.60 \\
\hline Eggshell Fragment & TDES 1 & -4.38 & -0.42 \\
\hline Eggshell Fragment & TDES 2 & -1.09 & -2.79 \\
\hline Eggshell Fragment & TDES 2 & -1.18 & -2.96 \\
\hline Eggshell Fragment & TDES 3 & -2.03 & -3.38 \\
\hline Eggshell Fragment & TDES 3 & -1.23 & -2.99 \\
\hline Eggshell Fragment & TDES 4 & -4.34 & -5.49 \\
\hline Eggshell Fragment & TDES 4 & -4.12 & -4.76 \\
\hline PCS Calcrete & TDPH 4A & -7.23 & -5.39 \\
\hline PCS Calcrete & TDPH 4B & -7.04 & -6.15 \\
\hline PCS Calcrete & TDPH 4C & -7.39 & -6.08 \\
\hline
\end{tabular}

owl predation on small to medium-sized primates come from Madagascar and the New World (Hart, 2007), with no suggestion to date of owls preying on primates the size of the Taung Child. The helmeted guinea fowl provided a good fit for one specimen (T92-88), while the surface curvature analysis indicated that fragment T93-17 was possibly derived from a black eagle egg or from a helmeted guinea fowl if overall size was not constrained.

Results of the surface morphology and curvature analyses narrowed taxonomical affinities of the T93-17 and T92-88 eggshells to either the black eagle or the helmeted guinea fowl. Each of these extant taxa has a distinct dietary ecology, a carnivore and a granivore / insectivore, respec- tively, aiding the use of carbon isotope palaeodietary analysis of fossil eggshells to discriminate between their source taxon. The modern black eagle has an eclectic diet consisting of small- to medium-sized mammals, which can range from $\mathrm{C}_{3}$ consumers (e.g., primates) to $\mathrm{C}_{4}$ consumers (e.g., hyraxes). Guinea fowl have a granivorous diet supplemented by insects and small mammals. They live and feed in open grassland, meaning that their diet is composed predominantly of $\mathrm{C}_{4}$ food-stuffs. Individuals responsible for T92-88 and the three small eggshell fragments have $\mathrm{a}_{4}$ dominated diet based on their carbon isotope composition (Figure 9). Of the extant avian taxa identified by micro- 


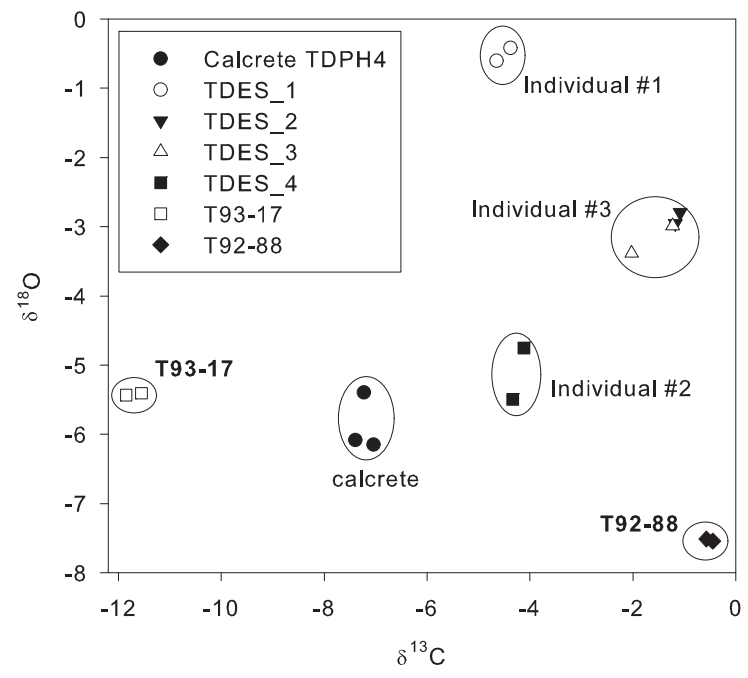

FIGURE 9. Cross-plot of oxygen and carbon isotope values from fossil eggshells and sediment, base of the Dart Pinnacle, Taung. There is a high degree of consistency between replicate samples, and each eggshell fragment shows a distinct isotopic signature, indicating that the eggshells are derived from different individuals (with the possible exception of TDES $2 \&$ TDES 3 ). The $\delta^{13} \mathrm{C}$ values indicate that all eggshells have a predominantly $\mathrm{C}_{4}$ (savannah grass) dietary signal, with the exception of T93-17 which has a pure (or almost pure) $\mathrm{C}_{3}$ diet.

scopic structure and curvature analyses, it is only the helmeted guinea fowl that has a diet consistent with the stable isotope composition of this fossil eggshell (Njiforti et al., 1998; Prinsloo et al., 2008). Fossil eggshells of ground-nesting birds are common in other hominin-bearing palaeosols (e.g., Harrison, 2005), and their nesting behaviour provides a simple taphonomic pathway for their deposition and preservation within the PCS deposit at Taung.

The $\mathrm{C}_{3}$ dominated diet of T93-17 is distinct from the other Taung eggshells, and cannot be attributed to a ground-nesting, $\mathrm{C}_{4}$ consuming species such as the helmeted guinea fowl. Instead, the $\mathrm{C}_{3}$ signal must be derived from the consumption of $\mathrm{C}_{3}$ plant material such as fruit, or perhaps indirectly through predation upon frugivourous and folivourous mammals or insects. For example, black eagles could maintain a $\mathrm{C}_{3}$ dominated isotopic signal through the consumption of $\mathrm{C}_{3}$ consuming prey (e.g., primates or rodents, respectively) (Gargett, 1990; Davies, 1999; Shultz, 2002; McGraw et al., 2006). It therefore remains plausible that T93-17 could be representative of an Aquilinae egg, with a specialised primate diet, in agreement with the bird-of-prey hypothesis for the accumulation of primate fossils at Taung.

This study indicates that the assumption made by McKee in 2001, that eggshell fragments recovered from the 'Dart deposit' were too small to be from an eagle egg or an owl egg, but possibly could have originated from a smaller bird egg such as that of a guinea fowl, appears to be correct for at least one of the analysed specimens, even though the use of overall size as a determining factor appears to be a non-factor when determining taxa of these particular fossil eggshells. The second fragment was more difficult to attribute to an avian taxon, but through the use of multiple lines of investigation, particularly isotopic analysis, it was determined to be most likely from a black eagle or related ancestor of Aquilinae.

The presence of guinea fowl (Numididae) eggs in the pink 'Dart' deposits would support a recent analysis of the pink deposits associated with both the Dart and Hrdlička pinnacles (Hopley et al., 2013). These deposits formed on the landscape and are not in fact cave deposits (Hopley et al., 2013). The presence of land-nesting bird eggs, such as helmeted guinea fowl, corroborates a landscape deposit; as opposed to the previously hypothesized cave deposit. The fact that no such eggshell fragments have been recovered from the red deposits, which appear to be cave infills, also appears more plausible.

\section{ACKNOWLEDGMENTS}

The University of the Witwatersrand provided access to the material. We thank L. Backwell from the University of the Witwatersrand for aiding in the microscopic photography; J. Limbachia of the Helen Joseph Hospital, Johannesburg, for the CT scans; Q. Letsoalo, S. Daya, I. Sealenyame, S. Padiachy, V. Mngomezulu, J.S. Smilg and M.D.T. Vangu of the Charlotte Maxeke Johannesburg Academic Hospital for assistance with CT scanning; J. Davy for assistance with the SEM imaging; M. Harmon, formerly of the Johannesburg Zoo, for his expertise in modern birds and bird eggs; T. Cassidy and G. Davies of the Ditsong National Museum of Natural History, Pretoria for use of comparative material; A. Sylvester for his assistance in selecting and performing an appropriate surface fitting procedure; T. Jashashvili for aid in producing the graphics from the CT scans; A. Kruger for aiding in the graphics; L. Norton and B. de Klerk for initial sorting of the Taung material. We also acknowledge editor J. Louys, style editor K. 
Black and the anonymous reviewers, all of whom greatly improved the manuscript.

\section{REFERENCES}

Baker, S.E. 2010. A taxonomic analysis of fossil fauna from Taung, North West province. Unpublished honours dissertation, University of the Witwatersrand, Johannesburg, South Africa.

Berger, L.R. 2006. Brief Communication: Predatory bird damage to the Taung type-skull of Australopithecus africanus Dart 1925. American Journal of Physical Anthropology, 131:166-168.

Berger, L.R. and Clarke, R.J. 1995. Eagle involvement in accumulations of the Taung child fauna. Journal of Human Evolution, 29:275-299.

Berger, L.R. and McGraw, W.S. 2007. Further evidence for eagle predation of, and feeding damage on, the Taung child. South African Journal of Science, 103:496-498.

Brain, C.K. 1981. The Hunters or the Hunted? University of Chicago Press, Chicago.

Broom, R. 1934. On the fossil remains associated with Australopithecus africanus. South African Journal of Science, 31:471-480.

Cheney, D.L. and Seyfarth, R.M. 1981. Selective forces affecting the predator alarm calls of vervet monkeys. Behaviour, 76:25-61.

Cooke, H.B.S. 1990. Taung fossils in the University of California collections, p. 119-134. In Sperber, G.H. (ed.), From Apes to Angels. Wiley-Liss, New York.

Csermely, D. 1996. Antipredator behavior in Lemurs: evidence of an extinct eagle on Madagascar or something else? International Journal of Primatology, 17:349-354.

Dart, R.A. 1925. Australopithecus africanus: the ManApe of South Africa. Nature, 115:195-199.

Dart, R.A. 1929. A note on the Taung skull. South African Journal of Science, 26:648-658.

Dart, R.A. and Craig, D. 1959. Adventures with the Missing Link. Harper Brothers, New York.

Davies, A.G. 1999. The extent, cost and control of livestock predation by eagles with a case study on black eagles (Aquila verreauxii) in the Karoo. Journal of Raptor Research, 33(1):67-72.

de Ruiter, D.J., Copeland, S.R., Lee-Thorp, J., and Sponheimer, M. 2010. Investigating the role of eagles as accumulating agents in the dolomitic cave infills of South Africa. Journal of Taphonomy, 8(1-2):129-154.

Fichtel, C., Perry, S., and Gros-Louis, J. 2005. Alarm calls of white-faced capuchin monkeys: an acoustic analysis. Animal Behaviour, 70:165-176.

Gargett, V. 1990. The Black Eagle: a Study. Acorn Books, Randburg.

Gilbert, C.C., McGraw, W.S., and Delson, E. 2009. Brief Communication: Plio-Pleistocene eagle predation on fossil cercopithecids from the Humpata Plateau, Southern Angola. American Journal of Physical Anthropology, 139:421-429.
Goodman, S.M. 1994. The enigma of antipredator behavior in lemurs: evidence of a large extinct eagle on Madagascar. International Journal of Primatology, 15(1):129-134.

Goodman, S.M. and Rakotozafy, M.A. 1995. Evidence for the existence of two species of Aquila on Madagascar during the Quaternary. Geobios, 28(2):241246.

Harrison, T. 2005. Fossil bird eggs from the Pliocene of Laetoli, Tanzania: their taxonomic and paleoecological relationships. Journal of African Earth Sciences, 41:289-302.

Harrison, T. and Msuya, C.P. 2005. Fossil struthionid eggshells from Laetoli, Tanzania: taxonomic and biostratigraphic significance. Journal of African Earth Sciences, 41:303-315.

Hart, D. 2007. Predation on primates: a biogeographical analysis, p.27-59. In Gursky-Doyen, S. and Nekaris K.A.I. (eds.), Primate Anti-Predator Strategies. University of Chicago, Chicago.

Hirsch, K.F. 1983. Contemporary and fossil chelonian eggshells. Copeia, 1983(2):382-397.

Hobson, K.A. 1995. Reconstructing avian diets using stable-carbon and nitrogen isotope analysis of egg components: patterns of isotopic fractionation and turnover. The Condor, 97:752-762.

Hopley, P., Herries, A.I.R., Baker, S.E., Kuhn, B.F., and Menter, C.G. 2013. Brief Communication: beyond the South African cave paradigm - Australopithecus africanus from Plio-Pleistocene paleosol deposits at Taung. American Journal of Physical Anthropology, 151:316-324. doi:10.1002/ajpa.22272

Hrdlička, A. 1925. The Taung ape. American Journal of Physical Anthropology, 8:379-392.

Johnson, B.J., Fogel, M.L., and Miller, G.H. 1998. Stable isotopes in modern ostrich eggshell: a calibration for paleoenvironmental applications in semi-arid regions of southern Africa. Geochimica et Cosmochimica Acta, 62:2451-2461.

Lee-Thorp, J.A., Sponheimer, M., and Luyt, J. 2007. Tracking changing environments using stable carbon isotopes in fossil tooth enamel: an example from the South African hominin sites. Journal of Human Evolution, 53:595-601.

McGraw, W.S., Cooke, C., and Shultz, S. 2006. Primate remains from African crowned eagle (Stephanoaetus coronatus) nests in Ivory Coast's Tai Forest: Implications for primate predation and early hominid taphonomy in South Africa. American Journal of Physical Anthropology, 131:151-165.

McKee, J.K. 2001. The Taung raptor hypothesis: caveats and new evidence. American Journal of Physical Anthropology, [Supplement] 32:107.

McKee, J.K. 2010. Taphonomic process of bone distribution and deposition in the tufa caves of Taung, South Africa. Journal of Taphonomy, 8(2-3):203-213.

Mikhailov, K.E. 1997. Avian Eggshells: an Atlas of Scanning Electron Micrographs. British Ornithologists' Club Occasional Publications, vol.3. 
Njiforti, H.L., Hebou, L., and Bodenkamp, A. 1998. Diet of the helmeted guineafowl (Numida meleagris galeata Pallas) in the Waza region of North Cameroon. African Journal of Ecology, 36(1):71-82.

Passey, B.H., Robinson, T.F., Ayliffe, L.K., Cerling, T.E., Sponheimer, M., Dearing, M.D., Roeder, B.L., and Ehleringer, J.R. 2005. Carbon isotope fractionation between diet, breath $\mathrm{CO} 2$, and bioapatite in different mammals. Journal of Archaeological Science, 32:1459-1470.

Prinsloo, H., Harley, V., Reilly, B., and Crowe, T. 2008. The diet of helmeted guineafowl (Numida meleagris) in the Riemland of the northeastern Free State, South Africa: short communication. South African Journal of Wildlife Research, 38(1):88-92.

Sanders, W.J., Trapani, J., and Mitani, J.C. 2003. Taphonomic aspects of crowned hawk-eagle predation on monkeys. Journal of Human Evolution, 44:87-105.

Schaffner, F.C. and Swart, P.K. 1991. Influence of diet and environmental water on the carbon and oxygen isotopic signatures of seabird eggshell carbonate. Bulletin of Marine Science, 48:23-38.

Shultz, S. 2002. Population density, breeding chronology and diet of Crowned Eagles Stephanoaetus coronatus in Taï National Park, Ivory Coast. Ibis, 144(1):135-138.

Struhsaker, T.T. 1967. Auditory communication among vervet monkeys (Cercopithecus aethiops), 281-324. In Altmann S.A. (ed.), Social Communication Among Primates. University of Chicago Press, Chicago.
Tarboton, W. 2001. A Guide to the Nests and Eggs of Southern African Birds. Struik, Cape Town, South Africa.

Tarboton, W. 2011. Roberts Nests and Eggs of Southern African birds. The John Voelcker Bird Book Fund, Cape Town.

Trapani, J., Sanders, W.J., Mitcani, J.C., and Heard, A. 2006. Precision and consistency of the taphonomic signature by crowned hawk-eagles (Stephanoaetus coronatus) in Kibale National Park, Uganda. Palaios, 21:114-131.

Val, A., Carlson, K.J., Steininger, C., Kibii, J.M., Churms, C., Kuhn, B.F., and Berger, L.R. 2011. 3D techniques and fossil identification: an elephant shrew hemimandible from the Malapa site. South African Journal of Science, 107:1-5.

von Schirnding, Y., Van der Merwe, N.J., and Vogel, J.C. 1982. Influence of diet and age on carbon isotope ratios in ostrich eggshell. Archaeometry, 24:3-20.

Winterbottom, J.M. 1971. Priest's Eggs of Southern African Birds Revised edition, Winchester Press, Johannesburg, South Africa.

Zipfel, B. and Berger, L.R. 2009. New Cenozoic fossil bearing site abbreviations for the collections of the University of the Witwatersrand. Palaeontologia Africana, 44:77-81.

Zuberbühler, K. 2001. Predator-specific alarm calls in Campbell's monkeys, Cercopithecus campbelli. Behavioral Ecology and Sociobiology, 50:414-422.

Zuberbühler, K., Noë, R., and Seyfarth, R.M. 1997. Diana monkey long-distance calls: messages for conspecifics and predators. Animal Behaviour, 53:589-604. 